\title{
HUBUNGAN MOTIVASI KERJA DENGAN PELAKSANAAN PENDOKUMENTASIAN PROSES KEPERAWATAN DI PUSKESMAS RIAM DURIAN
}

\author{
${ }^{1}$ Rahaju Wiludjeng,SE.,MM \\ ${ }^{1}$ STIKes Borneo Cendekia Medika Pangkalan Bun \\ ${ }^{1}$ Email : ira.wiludjeng@gmail.com
}

\begin{abstract}
ABSTRAK
Motivasi dan kemampuan melaksanakan pelayan keperawatan merupakan unsur utama didalam kinerja seorang Perawat. Kemampuan melaksanakan tugas merupakan unsur utama didalam menilai kinerja seseorang tetapi tanpa didukung oleh adanya suatu kemauan dan motivasi, maka tugas tidak akan dapat diselesaikan. Setiap aspek dari pengobatan dan perawatan pasien yang dilakukan oleh tim pelayanan kesehatan harus didokumentasikan sehingga dapat memberikan gambaran keseluruhan dari kondisi kesehatan pasien. Tujuan dari penelitian ini adalah menganalisis hubungan motivasi kerja dengan pelaksanaan pendokumentasian proses keperawatan. Penelitian ini adalah penelitian analitik korelasional dengan menggunakan pendekatan cross sectional. Populasi dalam penelitian ini adalah semua perawat di rawat inap puskesmas Riam Durian Kabupaten Sukamara. Teknik sampling yang digunakan adalah total sampling. Hasil uji statistik dengan menggunakan rumus Spearman's rho didapatkan nilai $\rho=0,016$ dan nilai $r_{s}=0,437$ dengan tingkat kemaknaan $\rho<0,05$, yang artinya ada hubungan antara motivasi kerja dengan pelaksanaan pendokumentasian proses keperawatan di Puskesmas Riam Kanan Kabupaten Sukamara. Saran : memberikan usul kepada Ke pala Puskesmas agar ada pembedaan insentif atau jasa bagi Perawat yang menjalankan pendokumentasian dengan baik dan lengkap.
\end{abstract}

\section{Kata Kunci : Motivasi kerja, pendokumentasian proses keperawatan}

\section{RELATIONSHIP OF WORK MOTIVATION WITH THE IMPLEMENTATION OF NURSING PROCESS IN PUSKESMAS RIAM DURIAN}

\section{ABSTRACT}

Motivation and the ability to carry out nursing services are the main elements in the performance of a nurse. The ability to carry out tasks is a major element in assessing a person's performance but without the support of a willingness and motivation, the task cannot be completed. Every aspect of patient care and treatment carried out by the health care team must be documented so as to provide an overall picture of the patient's health condition. The purpose of this study is to analyze the relationship between work motivation and the implementation of documentation of the nursing process. This research is a correlational analytic study using a cross sectional approach. The population in this study were all nurses in the inpatient clinic of Riam Durian Health Center in Sukamara Regency. The sampling technique used is total sampling. Statistical test results using the Spearman's formula obtained value $\square=$ 0.016 and $r$ s value $=0.437$ with a significance level $\square<0.05$, which means that there is a relationship between work motivation with the implementation of 
documentation of the nursing process at the Riam Kanan Health Center in Sukamara District. Suggestion: give a proposal to the Head of Puskesmas so that there is a differentiation of incentives or services for Nurses who carry out the documentation properly and completely.

\section{Keywords: work motivation, documentation of the nursing process}

\section{PENDAHULUAN}

Pelayanan Keperawatan merupakan bagian integral dari pelayanan kesehatan dan merupakan cermin utama dari keberhasilan pelayanan kesehatan secara keseluruhan. Suatu pelayanan yang bermutu tinggi harus dilaksanakan oleh tenaga profesional dengan cara profesional juga. Pelayanan Keperawatan merupakan bagian integral dari pelayanan kesehatan dan merupakan cermin utama dari keberhasilan pelayanan kesehatan secara keseluruhan. Dokumentasi keperawatan merupakan catatan permanen tentang apa yang terjadi pada klien, disamping sebagai persyaratan akreditasi yang merupakan syarat legal dalam pelayanan kesehatan. Fungsi dokumentasi bagi perawat salah satunya sebagai alat komunikasi serta bukti pertanggungjawaban pelaksanaan kegiatan keperawatan. Masih tingginya angka ketidaklengkapan pendokumentasian proses keperawatan tersebut harus diantisipasi dengan menekan beberapa faktor diantaranya selalu melakukan evaluasi mengenai kelengkapan pendokumentasi serta motivasi kinerja Perawat itu sendiri. Kinerja seorang Perawat yang bekerja di pelayanan perawatan, kinerjanya akan dipengaruhi juga oleh motivasi kerjanya. Motivasi dan kemampuan melaksanakan tugas merupakan unsur utama didalam kinerja seorang Perawat. Motivasi merupakan suatu usaha yang disadari untuk mengetahui tingkah laku seseorang agar ia tergerak hatinya untuk bertindak melakukan sesuatu sehingga tercapai hasil atau tujuan tertentu. Tanpa motivasi orang tidak akan dapat berbuat apa-apa, tidak akan bergerak.

\section{METODOLOGI PENELITIAN}

Penelitian ini merupakan penelitian analitik korelasional dengan pendekatan cross sectional. Populasi dalam penelitian ini adalah semua Perawat di rawat inap puskesmas Riam Durian Kabupaten Sukamara. Sedangkan status pasien (data rekam medik), jumlah sampel yang digunakan adalah data rekam medik yang diperoleh dalam kurun waktu yang digunakan oleh peneliti. Pada penelitian ini untuk populasi perawat menggunakan total sampling, sedangkan untuk data rekam medik menggunakan consecutive sampling. Penelitian ini menggunakan uji analisa data statistik korelasi spearman.

\section{HASIL PENELITIAN}

\section{A. Data Umum}

Hasil perhitungan karakteristik responden menunjukkan bahwa lebih dari sebagian besar responden berjenis kelamin perempuan yaitu sebanyak 24 orang $(80 \%)$, sebagian besar responden berumur $31-40$ tahun yaitu sebanyak 23 responden $(76,7 \%)$, sebagian besar responden status perkawinan kawin adalah sebanyak 27 responden (90\%), hampir seluruhnya responden 
berpendidikan AKPER yaitu sebanyak 28 responden $(93,3 \%)$ dan sebagian besar responden sebagai PNS yaitu sebanyak 27 responden (90\%).

B. Data Khusus

Berdasarkan motivasi kerja kerja responden kategori tinggi yaitu sebanyak 18 responden $(60 \%)$, sebagian besar responden melaksanakan pendokumentasian proses keperawatan lengkap yaitu sebanyak 19 responden $(63,4 \%)$. Hasil penelitian menunjukkan bahwa sebagian responden memiliki motivasi kerja tinggi dengan pelaksanaan pendokumentasian proses keperawatan lengkap di Puskesmas Riam Durian Kabupaten Sukamara sebanyak 14 responden $(46,7 \%$ ). Berdasarkan hasil uji statistik dengan menggunakan rumus Spearman's rho didapatkan nilai $\rho=0,016$ dan nilai $r_{s}=0,437$ dengan tingkat kemaknaan $\rho<0,05$ yang berarti $\mathrm{H}_{0}$ ditolak dan $\mathrm{H}_{1}$ diterima, jadi ada hubungan antara motivasi kerja dengan pelaksanaan pendokumentasian proses keperawatan di Puskesmas Riam Durian Kabupaten Sukamara.

\section{PEMBAHASAN}

Pendokumentasian proses keperawatan dipengaruhi oleh motivasi kerja dari perawat. Sesuai dengan hasil penelitian menunjukkan bahwa dari 30 responden, sebanyak 14 responden $(46,7 \%)$ memiliki motivasi kerja yang tinggi dengan pelaksanaan pendokumentasian yang lengkap di Puskesmas Riam Durian Kabupaten Sukamara.

Hal ini sesuai dengan hasil uji statistik dengan menggunakan rumus Spearman's rho didapatkan nilai $\square=$ 0,016 dan nilai $r_{\mathrm{s}}=0,437$ dengan tingkat kemaknaan $\square<0,05$ yang berarti $\mathrm{H}_{0}$ ditolak dan $\mathrm{H}_{1}$ diterima, jadi ada hubungan antara motivasi kerja dengan pelaksanaan pendokumentasian proses keperawatan di Puskesmas Riam Durian Kabupaten Sukamara. Dari hasil analisis penelitian tentang hubungan motivasi kerja Perawat dengan pelaksanaan pendokumentasian proses keperawatan dapat diartikan bahwa semakin tinggi motivasi kerja Perawat akan diikuti oleh semakin baiknya pelaksanaan pendokumentasian proses keperawatan. Menurut Munandar (2002) dalam bukunya menguraikan tentang kaitan motivasi kerja dengan unjuk kerja dapat diungkapkan bahwa unjuk kerja (performance) adalah hasil interaksi antara motivasi kerja, kemampuan (abilities), dan peluang (opportunities), dengan perkataan lain unjuk kerja adalah fungsi dari motivasi kerja kali kemampuan kali peluang. Bila motivasi kerja rendah, maka unjuk kerjanya akan rendah pula meskipun kemampuannya ada dan baik, serta peluangnya pun tersedia.

\section{KESIMPULAN DAN SARAN}

\section{A. Kesimpulan}

1. Sebagian besar responden di Puskesmas Riam Durian Kabupaten Sukamara memiliki motivasi kerja yang tinggi

2. Sebagian besar responden di Puskesmas Riam Durian Kabupaten Sukamara melaksanakan pendokumentasian proses keperawatan dengan lengkap.

3. Ada hubungan antara motivasi kerja Perawat dengan pelaksanaan pendokumentasian proses keperawatan di Puskesmas Riam Durian Kabupaten Sukamara. 


\section{B. Saran}

a. Bagi Responden (Perawat)

Sebaiknya responden atau

Perawat memiliki motivasi kerja yang tinggi sesuai dengan tanggung jawabnya sebagai Perawat profesional, dengan cara selalu melakukan pencatatan dengan tepat sesuai dengan kondisi dan perkembangan pasien. Adanya pembagian tugas dan tanggung jawa yang diberikan Kepala Ruangan kepada masing-masing Perawat pelaksana untuk memenuhi atau menyelesaikan tugas yang dibebankan.

b. Bagi Puskesmas

1) Kepala Rawat Inap melakukan fungsi kontrol terhadap staf dengan memberikan target pelaksanaan pendokumentasian pada masing-masing staf sehingga mampu menilai kinerja staf tersebut dan memberikan apresiasi terhadap hasil kinerja yang bersangkutan. Memberikan atau melakukan supervisi secara berkala terhadap kelengkapan pendokumentasian proses keperawatan.

Memberikan usul kepada Kepala Puskesmas agar ada pembedaan insentif atau jasa bagi Perawat yang menjalankan pendokumentasian dengan baik dan lengkap. Dengan harapan mampu memacu semangat kinerja bagi sebagian Perawat yang memiliki motivasi belum tinggi untuk dapat menyelesaikan tugastugasnya.

2) Bagian Rekam Medis Memberikan umpan balik terhadap hasil pendokumentasian proses keperawatan tiap satu bulan sekali.

c. Bagi peneliti selanjutnya

Untuk mengembangkan penelitian yang akan datang sebaiknya peneliti selanjutnya menggunakan metode penelitian yang lain, sampling yang berbeda dan menggunakan sumber literatur yang terbaru dan lebih bermutu guna mendapatkan hasil yang sempurna misalnya :

1) Jumlah sample yang mempunyai nilai presisi tinggi :Hubungan motivasi kerja Perawat dengan pelaksanaan pendokumentasian proses keperawatan di Puskesmas Kalitidu Kabupaten Bojonegoro.

2) Faktor-faktor yang mempengaruhi kelengkapan pendokumentasian proses keperawatan di ruangan yang menggunakan MAKP dan non MAKP,atau judul yang lebih spesifik lagi

d. Bagi institusi pendidikan

1) Diharapkan mengembangkan penelitian mengenai manajemen keperawatan.

2) Menjadikan dasar acuan penyusunan kurikulum khususnya ilmu manajemen keperawatan.

DAFTAR PUSTAKA 
Aditama, Candra Yoga. Manajemen Administrasi Rumah Sakit. Edisi 2. Jakarta. UI.

Alen, Carol Vestal, 1998. Comprehending the nursing process. A workbook approach. Jakarta. EGC.

Arikunto, Suharsimi, 1998. Prosedur Penelitian Suatu Pendekatan Praktek. Jakarta. Rineka Cipta.

Arikunto, Suharsismi, 2000. Manajemen Penelitian. Jakarta. Rineka Cipta.

Doenges, Marlyn,1998. Application of nursing process and diagnosis: an interactive texs for diagnostic reasoning.Edisi 2.EGC.

Effendy, Nasrul, 1995. Pengantar Proses Keperawatan. Jakarta. EGC.

Hidayat, A. Azis Alimul, 2003. Riset Keperawatan \& Tehnik Penulisan Ilmiah. Jakarta. Salemba Medika.

Hidayat, A. Azis Allimul, 2001. Pengantar Dokumentasi Proses Keperawatan. Jakarta. EGC.

Johanes Papu , 2007 ., Faktor-Faktor yang Mempengaruhi Motivasi., www.epsikologi.com/masalah/faktor.ht $m$ - 31k -, diakses 3 September 2008

Monica, Elaine L.La, 1998. Nursing leadership and Management: an experiential approach. Jakarta. EGC.
Munandar, Ashar Sunyoto, 2001. Psikologi industri dan organisasi. Jakarta .UI.

Notoatmodjo, Soekidjo, 2002. Metodologi Penelitian Kesehatan. Edisi 2. Jakarta. PT RINEKA CIPTA.

Nursalam, 2001. Proses \& Dokumentasi Keperawatan: Konsep \& Praktek, Jakarta. Salemba Medika.

Nursalam, M.Nurs, 2002. Manajemen Keperawatan: Aplikasi dalam Praktik Keperawatan Profesional. Jakarta. Salemba Medika.

Nursalam, 2003. Konsep \& Penerapan Metodologi Penelitian Ilmu Keperawatan: Pedoman Skripsi, Tesis dan Instrumen Keperawatan. Jakarta. Salemba Medika.

Pedoman Penulisan Laporan Tugas Akhir. Edisi 2. Malang. Universitas Brawijaya.

Purwanto, Heri. 1998. Pengantar Perilaku Manusia untuk Keperawatan. Jakarta.EGC.

Riduwan, 2002. Skala Pengukuran Variabel-Variabel Penelitian. Bandung. ALFABETA.

Thoha, Miftah. 2002. Perilaku Organisasi Konsep Dasar dan Aplikasinya. Edisi 13. Jakarta. PT Raja Grafindo Persada.

Taylor, Carol, Lilis, Priscilla. 1997. Fundamental of Nursing. Third Edition. Philadelphia. New york. Lippicott 
Winardi, J, 2002. Motivasi dan Pemotivasian dalam Manajemen. Jakarta. PT raja Grafindo Persada.

Widayatun, Tri Rusmi. 1999. Ilmu Perilaku. PT Fajar Interpratama. 